\title{
Erratum to: P53 immunoexpression as a prognostic marker for human astrocytomas: a meta-analysis and review of the literature
}

Georgia Levidou • Elias El-Habr • Angelica A. Saetta • Christine Bamias • Klea Katsouyanni •

Efstratios Patsouris • Penelope Korkolopoulou

Published online: 18 June 2010

(C) Springer Science+Business Media, LLC. 2010

Erratum to: J Neurooncol

DOI 10.1007/s11060-010-0204-y

There was an error in the name of the fifth author in the original publication. The author names in this erratum are correct.

The online version of the original article can be found under doi: 10.1007/s11060-010-0204-y.

G. Levidou ( $₫)$ · E. El-Habr · A. A. Saetta · E. Patsouris · P. Korkolopoulou

Medical School, Department of Pathology, Laiko Hospital, National and Kapodistrian University of Athens, 11527 Athens,

Greece

e-mail: glevidou@yahoo.gr

G. Levidou · C. Bamias · K. Katsouyanni

Department of Hygiene, Epidemiology and Medical Statistics,

University of Athens, 11527 Athens, Greece 